\title{
Erratum to: Measuring Ageism Based on Knowledge, Attitudes and Behavior: Findings from an Israeli Pilot Study
}

\author{
Sharon Shiovitz-Ezra ${ }^{1} \cdot$ Liat Ayalon $^{2}$. \\ Jenny Brodsky ${ }^{3} \cdot$ Israel (Issi) Doron $^{4}$
}

Published online: 27 July 2016

(C) Springer Science+Business Media New York 2016

\section{Erratum to: Ageing International \\ DOI 10.1007/s12126-016-9251-9}

This article had previously been published in Hebrew as a chapter in: Doron, I. (Ed.) (2013). Ageism in the Israeli Society: The Social Construction of Old Age. Jerusalem: The Van Leer Jerusalem Institute / Hakibbutz Hameuchad Publishing House.

The online version of the original article can be found at http://dx.doi.org/10.1007/s12126-016-9251-9.

Israel (Issi) Doron

idoron@univ.haifa.ac.il

Sharon Shiovitz-Ezra

sharonshi@mscc.huji.ac.il

Liat Ayalon

ayalonl@mail.biu.ac.il

Jenny Brodsky

JennyB@jdc.org.il

1 Paul Baerwald School of Social Work and Social Welfare, The Hebrew University of Jerusalem, Mount Scopus, 91905 Jerusalem, IL, Israel

2 Gabi and Louis Weisfeld School of Social Work, Faculty of Social Sciences, Bar-Ilan University, Ramat Gan, Israel

3 Center for Research on Aging, Brookdale Institute, JDC, Jerusalem, Israel

4 Department of Gerontology \& School of Social Work, Faculty of Welfare and Health Sciences, University of Haifa, Haifa, Israel 